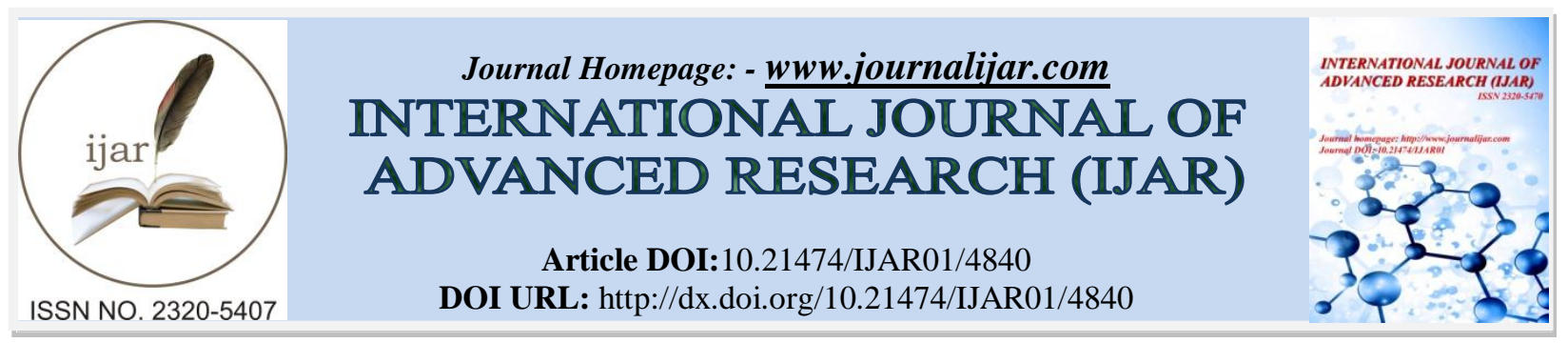

RESEARCH ARTICLE

DEVELOPMENT AND STANDARDISATION OF MATHEMATICAL CREATIVITY TEST.

Dr. Pooja Walia ${ }^{1}$ and Dr. Puneet Walia ${ }^{2}$.

1. Assistant Professor, Central University of Haryana, India.

2. Principal, NC College of Education, Panipat, Haryana, India.

\section{Manuscript Info}

Manuscript History

Received: 13 May 2017

Final Accepted: 15 June 2017

Published: July 2017

Key words:-

Mathematical creativity, Reliability, Validity.

\section{Abstract}

Mathematical creativity is the process of producing more than one response of mathematical problem. Researcher framed some items to assess the mathematical creativity of eighth grade students. This MCT followed one criterion's of mathematical creativity i.e. divergent thinking having three dimensions: Fluency, Flexibility and Originality. Items were formulated and selected by following required steps. The test was standardized by establishing reliability and validity of items. Split- half reliability was calculated and it was found 0.89 which is significant. Content validity of the test was determined by the teachers from different schools. Product moment co-relation was used to determine Concurrent validity. It was found 0.50 which is significant.

Copy Right, IJAR, 2017,. All rights reserved.

Tammadge (1979) stated that there is an urgent need for mathematics teachers to identify, encourage and improve creative mathematical ability at all levels. He argued that mathematics teaching has for too long been dominated by a rational thought/rote learning model, with an emphasis on cumulative learning of existing knowledge (Haylock, 1987). Situation is the same in recent scenario of mathematics teaching. Most of the teachers considered mathematics a subject of numbers and calculations. The way of teaching mathematics in classroom is not changed yet now. Deductive method of teaching is commonly used in most of the schools. This method does not provide the students to think divergently. Students have to solve the problems based on the formula that derived by the teacher. If mathematics teachers are asked to find creativity in mathematics among students they have no idea about this aspect of thinking. Because they feel that only one answer is existed for a particular question in mathematics. There is a need to design some problems and situations for students that helps to arouse their creativity.

\title{
Mathematical Creativity:-
}

"Mathematical creativity is an ability of analyzing a given problem in a variety of ways, based on existing knowledge and experience, breaking from fixed patterns, and obtaining a result by combining the factors of a problem with mathematical ideas in a new way. That is, creativity in mathematics should first give weight to the correct introduction of existing notions. Even though creativity relates to the production of certain new results, it appears to be more closely related to new analysis of a problem, new approaches and new ways of problem-solving. Accordingly, creativity in mathematics represents mathematical thinking of the highest level" (Kim, Lee \& Cho, 1999).

Ervynck's (1991) defined "Mathematical creativity is the ability to solve problems and/or to develop thinking cognitive structures about a mathematical concept or set of concepts considering both the historical development of a concept as well as its logico-deductive framework". 
"Einstein is quoted as saying that the ability to see the problem is more important than the ability to solve it, and so the operational definition of creativity in mathematics is concerned with the ability to produce problems rather than with the ability to find unusual or unique solutions to a given problem" (Dunn, 1975).

Fetterly, 2010 stated that even though no single definition encompasses the essence of mathematical creativity (Haylock, 1987a; Pehkonen, 1997). It is generally described in terms of three major components: fluency, flexibility, and originality. Fluency is the frequency or number of responses. Flexibility is the shift in categories or methods in the responses to a mathematical task. Originality is when a response is novel compared to other responses".

There are many tests available to assess general creativity of students as Torrance Tests of Creative Thinking, Mehdi's Tests of Creativity, Passi's Tests of Creativity, Wallach \& Kogan Tests of Creativity, Tiwari \& Chauhan's Tests of Creativity. To assess the mathematical creativity of the students few test has been developed. Dunn (1974) stated that "The first of these kinds has been evident in a number of attempts in recent years to create tests which purport to measure ' mathematics creativity ' (almost all of these tests have emerged in doctoral dissertations in America) Spraker (1960), Prouse (1964), Evans (1965), Buckeye (1968), Baur (1970), Meyer (1970), Mainville (1972) and Jensen (1973). Apart from these Khedre (1968), Sawhney (1968), Foster (1969) and Jensen (1973) developed tests to assess mathematical creativity. Haylock (1984) devised an instrument contains 20 multiple choice mathematical items. Creative ability in mathematics (CAMT) developed by Balka (1974) by taking two criteria of mathematical creativity i.e. divergent thinking and convergent thinking (Mann, 2006).

Some Indian researchers ( Singh; 1984, Miyan; 1982, Tull; 1985, Srivastava; 1987, Biswal ;1997) have developed tests on mathematical creativity. Besides the above Indian researcher Kapur (1976) and Chauhan(1977) have also given some thoughts for the measurement of creativity in mathematics. Singh (1984) developed the test to assess creativity in Arithmetic. Lee, Hwang, \&Seo (2003) developed a test, which can be used in creative problem solving ability of the mathematically gifted and the regular students. Sayed \& Demerdash (2008) constructed and standardized geometric creativity test. Geometry creativity test assess only geometrical area of mathematics. Mathematics is a combination of Arithmetic, Algebra, Geometry, Mensuration etc. Mathematical creativity test should cover all the important areas. Avjit (2011) constructed a tool to assess mathematical creativity in Bangali medium school students. Sharma \& Sansanwal (2012) developed Mathematical Creativity Test consisted of 20 items to assess the mathematical creativity of the $9^{\text {th }}$ and $10^{\text {th }}$ grade students. Manchanda (2013) developed and standardized mathematical creativity test to see the effect of abacus arithmetic programme on mathematical creativity on third grade students. These tests were constructed for specific purposes and classes. There is much scope to develop test for different classes.

Mathematical creativity is the ability which should be assessed at each level of school education. To assess mathematical creativity of students of Indian culture, there is a need to do more work in this area. The present test is an attempt to meet the need to assess mathematical creativity of eighth grade students.

\section{Dimensions of Mathematical Creativity Test:-}

This MCT followed one criterion's of mathematical creativity i.e. divergent thinking having three dimensions: Fluency, Flexibility and Originality. Gupta (1979) defined the three dimensions in context to scientific creativity. Researcher adapted these definitions of Gupta (1979) in context to mathematical creativity.

\section{Fluency:-}

Fluency is a matter of facility with which an individual retrieves responses from his personnel information in storage to a new mathematical situation. It is termed as frequency or number of responses.

\section{Flexibility:-}

Flexibility is a matter of fluidity of information or lack of fixedness or rigidity. It is known as the shift in categories or methods in the responses to a mathematical task.

Originality:-

Originality or novel output implies new and unusual uses of retrieved information. 
Researcher constructed and standardized this test by following the required steps viz. Planning and Writing of the test items, Try-out, Item Analysis, Selection of items for the final draft and determination of reliability and validity of the test.

\section{Steps of Construction of Test:- Planning and Writing of the Test:-}

Researcher planned to formulate such items that assess three dimensions of mathematical creativity i.e. fluency, flexibility and originality. Initially twenty eight items were formulated and selected from different books of eighth grade mathematics.

\section{Reviewing and Editing of the Items:-}

Ten school mathematics teachers were consulted for selection of the items for this test. It had been also reviewed with the help of senior practicing teachers and expert teacher educators in the field of Mathematics. Some of the items had been reworded, modified and deleted based on their suggestions. Concise directions indicated the duration of the test, difficulty level and language of the items. After edited by the mathematics teachers, it was reviewed by language expert. Some grammatical corrections were made. Out of twenty eight items only fifteen items were selected for the try outs.

\section{Pre Tryouts:-}

Ten students from Gurukul, Kurukshetra were chosen for individual try out to see difficulties faced by the students. Most of the students feel fatigue to complete the test due to divergent type of items. Researcher deleted those items which were left by most of the students. Researcher selected eight items on the basis of pre tryouts results.

\section{General Format of the Preliminary Draft:-}

Preliminary draft consisted of eight items. Items for the present test were designed based on assumptions adapted from Creative Abilities in Mathematics Test of Balka (1974). Description of test items as follows

Item I was designed to provide the opportunity to break established mind sets. Item II was developed to assess the formulation of mathematical hypotheses concerning cause and effect in mathematical situations. A mathematical game was planned to determine geometric figure by asking some questions. Item III provided the opportunity to see the relationships between numbers. Item IV consisted of two figures which were similar in certain aspects and different in another. Students had to write as many responses about similarities and dissimilarities of these two figures. Item $\mathrm{V}$ provided the opportunity to relate the knowledge of geometrical ideas with the surroundings. Item VI provided the opportunity to determine patterns in mathematical situations. Some numbers were presented to students. They had to choose few numbers in order to have some relation with each other or follow some rule or patterns. Item VII provided the opportunity to pose problems in a mathematical situation. Item VIII helped to imagine abstract geometrical figures with concrete things.

\section{Try Out:-}

Try out is most important step in construction of the test. Under this head there are two subheads which have equal importance to describe i.e. Data Collection and Scoring Procedure

\section{Data Collection:-}

A sample of ninety two students of eighth grade of D.A.V. Public School affiliated to C.B.S.E. board of Kurukshetra district of Haryana were chosen for the try-out of the test. There were 288 Students among six sections. Each section had 48 students. Two sections were chosen randomly to administer the test. Age of the students lied between $13^{\text {th }}$ to $14^{\text {th }}$ years. Duration of 1 hours and 20 minutes was fixed to complete the test which was manageable in term of administration and avoidance of the fatigue.

Some orientation was provided about mathematical creativity. Difference between three dimensions i.e. fluency, flexibility and originality was told to the students by the researcher. Whole test was introduced as a game to create relaxed atmosphere. Students recorded their responses in the test booklets.

\section{Scoring Procedure:-}

Most of the studies related to creativity considered three dimension of creativity i.e. fluency, flexibility and originality. Balka (1974), Goyal (1974), Gupta (1979), Miyan (1982) and Singh (1984) also measured fluency, 
flexibility and originality. Mehndi (1973) measured these three dimensions as well elaboration also. Researcher considered three dimensions for which scoring was done.

\section{Weight age to Different Dimensions:-}

The test items were scored for all the three dimensions of creativity viz., fluency, flexibility and originality in the manner described below.

Fluency: An individual's score for fluency was determined by counting the total number of relevant and correct responses given by the students to a particular item. One mark was given for each response but no additional mark is given to the repetitive responses. The main stress was on relevant and correct responses, because in a mathematical creativity test, responses should be mathematically accurate.

Flexibility: Flexibility score was measured by counting the total number of categories, in which students responses could be classified. Every category was given a credit of one mark.

Originality: It was assessed on the basis of uncommonness of responses. Originality scores were based on category weights that reflected the percentage of sample. A score 0 to 5 was assigned to different responses according to their categories. Response given by more than $5 \%$ of the respondents got score 0 . Response given by $4 \%$ to $5 \%$ of the respondents got score 1 . Response given by $3 \%$ to $4 \%$ of the respondents got score 2 . Response given by $2 \%$ to 3 $\%$ of the respondents got score 3 . Response given by $1 \%$ to $2 \%$ of the respondents got score 4 . Response given by less than $1 \%$ of the respondents got score 5. The summated score of fluency, flexibility and originality yielded an estimate of total mathematical creativity.

\section{Item Analysis:-}

Item analysis is one of the essential steps in the construction of the test. It is primarily concerned with item difficulty and item discrimination. Item difficulty is taken in terms of the proportion of individuals completing the item successfully and its discrimination index refers to the degree to which it differentiates between those obtaining high and low scores. In creativity test, item difficulty could not be determined in the conventional way due to divergent thinking items. The item analysis was based on the scores of a sample of 92 students from D.A.V. public school, Kurukshetra. The items were analysed on the basis of calculation of item discrimination in terms of $\mathrm{t}$ - ratio by taking Upper and lower $27 \%$ cases of sample.

Table I:-Significance of Difference between Upper Group and Lower Group Scores in Preliminary Draft (MCT)

\begin{tabular}{|c|c|c|c|c|c|c|}
\hline \multirow[t]{2}{*}{ Item No. } & \multicolumn{2}{|c|}{ Upper Group } & \multicolumn{2}{|c|}{ Lower Group } & \multirow[t]{2}{*}{ t-ratio } & \multirow[t]{2}{*}{$S_{\text {E.D. }}$} \\
\hline & $\mathbf{M}_{1}$ & S.D. 1 & $\mathbf{M}_{2}$ & S.D. 2 & & \\
\hline I & 28.04 & 4.79 & 12.88 & 3.61 & 12.63 & 1.20 \\
\hline II & 39.44 & 6.24 & 13.8 & 4.70 & 16.41 & 1.56 \\
\hline III & 24.4 & 5.01 & 10.04 & 2.31 & 13.05 & 1.10 \\
\hline IV & 26.56 & 3.87 & 11.6 & 2.77 & 15.69 & 0.95 \\
\hline $\mathrm{V}$ & 44.88 & 7.92 & 16.36 & 4.42 & 15.73 & 1.813 \\
\hline VI & 23.8 & 7.44 & 3.72 & 2.92 & 12.63 & 1.59 \\
\hline VII & 25.88 & 4.43 & 8.88 & 2.25 & 17.10 & .99 \\
\hline VIII & 26 & 7.51 & 8.04 & 3.19 & 11.01 & 1.63 \\
\hline
\end{tabular}

Level of Significance- 0.01

Table I shows that all the t-values are highly greater than the table value at $\mathrm{df}=48$.

Selection of Items for the Final Draft:-

All the items differed significantly between Upper and lower group. All the items were selected for the final draft (Appendix A). Before finalize the test items, their item validity and factor validity were also determined.

\section{Item Validity:-}

Item validity is an important criterion to studying the usefulness of the items in a test. Mehndi (1973), Singh (1985) measured item validity. Item validity was determined by establishing correlation between each item score and total mathematical creativity score. The raw scores for each item were converted into t-scores with a mean of 50 and SD 10 was added up to get total score for each item. 
Table II:-Correlation Coefficients for Item Scores and Total Mathematical Creativity Scores

\begin{tabular}{|c|c|c|}
\hline Sr. No. & Relationship between different items score and Total Mathematical creativity score & r \\
\hline 1. & Item I vs. Total Mathematical creativity & 0.41 \\
\hline 2. & Item II vs. Total Mathematical creativity & 0.72 \\
\hline 3. & Item III vs. Total Mathematical creativity & 0.55 \\
\hline 4. & Item IV vs. Total Mathematical creativity & 0.67 \\
\hline 5. & Item V vs. Total Mathematical creativity & 0.63 \\
\hline 6. & Item VI vs. Total Mathematical creativity & 0.56 \\
\hline 7. & Item VII vs. Total Mathematical creativity & 0.58 \\
\hline 8. & Item VIII vs. Total Mathematical creativity & 0.45 \\
\hline
\end{tabular}

Significance $=0.01, \mathrm{~N}=92, \mathrm{df}=90$

Table II shows that each item in the test is correlated with the total scores. It is indicated that items are measuring mathematical creativity individually and pointing to the fact that items are highly internally consistent.

\section{Factor validity:-}

Factor validity is concerned with the factors included in a test. In the present test three factor were included, fluency, flexibility and originality. Separate scores for all the three factors were obtained and correlated among themselves and with the total mathematical creativity score. The correlations between the different factors of mathematical creativity and the total mathematical creativity scores are presented in table III.

Table III:-Correlation Coefficients for Various Factors of Mathematical Creativity and the Total Mathematical Creativity Scores

\begin{tabular}{|c|l|c|c|c|c|}
\hline Sr. No. & Factor & Fluency & Flexibility & Originality & $\begin{array}{c}\text { Total Mathematical } \\
\text { Creativity }\end{array}$ \\
\hline 1. & Fluency & 0.00 & 0.84 & 0.40 & 0.86 \\
\hline 2. & Flexibility & 0.84 & 0.00 & 0.48 & 0.86 \\
\hline 3. & Originality & 0.40 & 0.48 & 0.00 & 0.80 \\
\hline 4. & Total Mathematical Creativity & 0.86 & 0.86 & 0.80 & 0.00 \\
\hline
\end{tabular}

Level of Significance $=0.01, \mathrm{~N}=92, \mathrm{df}=90$

Table III shows correlation among the factors and total mathematical creativity scores. All correlations are significant at 0.01 level. It is indicated that the all three factors have equal importance to judge mathematical creativity of the students. On the basis of item and factor validity eight items were selected for the final draft. After selection of the items, standardization of items was determined in terms of reliability and validity.

\section{Determination of Reliability \& Validity:-}

Operationally, reliability of the test refers to the consistency of scores obtained by the same individuals (Gupta, 1979). Reliability of MCT was calculated by split-half method. Two scores were obtained for each individual on the two comparable halves and correlation was found for these half tests. In the present case, the odd-even splitting was not possible as the items were not arranged in ascending order of difficulty, like convergent ability tests, due to great heterogeneity in the items. Hence, it was decided to split the halves on the basis of the mean value of the items. From a total sample of 92 students, half of the students i.e. 46 were selected at random for computing reliability. Considering forty six students, means score of all the eight items were calculated and arranged in an ascending order of mean value and the successive pairs in the list.

After that the scores on these items of the two halves were found out separately to compute the Product Moment Correlation. Coefficient of correlation was found on each factor of mathematical creativity i.e. fluency, flexibility, originality and total creativity. It was found $0.66,0.64,0.57$, and 0.79 respectively. From the correlation of these half tests, the reliability coefficient of the whole test was estimated with the help of Spearman-Brown prophecy formula. Reliability coefficients of the whole mathematical creativity test and its factors are presented in table IV. 
Table IV:-Reliability Coefficients for MCT

\begin{tabular}{|c|c|c|}
\hline Sr. No. & Factor & R \\
\hline 1 & Fluency & 0.79 \\
\hline 2 & Flexibility & 0.78 \\
\hline 3 & Originality & 0.73 \\
\hline 4 & Total Mathematical Creativity & 0.89 \\
\hline
\end{tabular}

Table IV shows the reliability coefficients of three factors and total mathematical creativity, ranging from 0.79 to 0.89. All coefficients of correlations are significant at 0.01 level. These values are highly satisfactory. It indicates the high consistency of the test.

\section{Validity:-}

The validity of a test may be defined as the accuracy with which it measures that which it intends to measure. Content validity was determined by mathematics experts. To determine the validity of the test statistically Concurrent validity was calculated. General creativity scores were obtained by using General Creativity Test developed by Mehndi (1973). General creativity scores and Mathematical creativity scores of forty six students was correlated. Coefficients of correlation were obtained between scores on all factors and total scores of Mathematical Creativity Test and General Creativity Test.

Table V:-Coefficient of Concurrent Validity for MCT

\begin{tabular}{|c|c|c|}
\hline Sr. No. & Factor & R \\
\hline 1. & Fluency & 0.66 \\
\hline 2. & Flexibility & 0.48 \\
\hline 3. & Originality & 0.18 \\
\hline 4. & Total mathematical creativity & 0.50 \\
\hline
\end{tabular}

Level of Significance $=0.01 \quad \mathrm{~N}=46, \mathrm{df}=44$

Fluency, flexibility and total mathematical creativity scores were found significantly correlated with those of general creativity of the students. Originality of mathematical creativity was not found significantly correlated with originality of general creativity. It is also conformity with findings of Singh (1984) i.e. insignificant correlation between originality of mathematical creativity and general creativity. It is interpretive as Originality is concerned with the knowledge and interest in particular subject. In case of general creativity there is no need of content knowledge but in mathematics content knowledge is important. It is not necessary that a student have high originality scores in general creativity also have good content knowledge in mathematics. It may be one of the reasons that no correlation was found between two scores of different tests.

\section{Administration and Scoring:-}

During administration main stress was on the relaxed atmosphere. Test was introduced as a game. As this test was new to the students so orientation was provide before the beginning of the test. Before every item two minutes were set to give orientation about each item. They informed after every seven minutes, to switch over to the next item. There was no room for talk to each other because it might affect the originality scores of the students. Students were allowed to clear any doubt or question in their mind. After cleared their doubts, test was begin and completed in one hour and twenty minutes.

\section{Scoring Key:-}

On the basis of responses given by the students during item analysis, tentative scoring key has been prepared by the researcher. Responses of each item put in different category namely A, B, C etc. These categories were used for flexibility scoring. Mehndi (1973) followed this criterion to score the flexibility dimension of creativity. Each category gained score one. An individual's score for fluency was determined by counting the total number of relevant and correct responses given by the students to a particular item. Originality was assessed on the basis of uncommonness of responses among the sample.

\section{Conclusion:-}

All the items of this Mathematical Creativity Test apparently measure the creative ability to handle mathematical situation. A teacher can assess the higher level objectives related to particular topic of the students by these test 
items. Item I help the teacher to evaluate arithmetical and algebraic knowledge of the students. Item II and IV help to know the properties of geometrical figures. Item III and Item VI related to number system and its relationship. Item V and VIII help to recognition of geometrical figures and concepts related to them. Item VII gives a direction towards the knowledge to handle mensuration, money and quantity of material. Whole test covers most of the topics included in the syllabus of eighth grade students. This test has a significant contribution in the field of mathematics and mathematics education. This test may be used by many researchers to assess mathematical creativity of eighth grade students. It is very helpful to assess mathematical creativity of eighth grade students.

\section{References:-}

1. Avjit, R. (2011). Development of a mathematical creativity test in Bengali medium school students. Journal of Korea Society in Mathematics Education, 15(1), 69-79.

2. Balka, D. S. (1974a). The development of an instrument to measure creative ability in mathematics. Dissertation Abstracts International, 36(1), 98.

3. Balka, D. S. (1974b). Creative ability in mathematics. Arithmetic Teacher, 21, 633-636.

4. Dunn, J.M. (1975). Tests of creativity in mathematics. International Journal of Mathematical Education in Science and Technology, 6(3), 327-332.Available online in 2006.

5. Ervynck, G. (1991). Mathematical creativity. In D. Tall (Ed.), Advanced mathematical thinking (pp. 42-52. New York: Kluwer Academic Publishers, In Sriraman, B. (2009). The characteristics of mathematical creativity. The Mathematics Educator, 14(1), 19-34.

6. Fetterly, J.M. (2010). An exploratory study of the use of a problem-posing approach on pre-service elementary education teachers' mathematical creativity, beliefs, and anxiety. Published Doctoral Dissertation, Florida State University, Florida.

7. Goyal, R.P. (1974). A test for measuring creativity among Indian children. Journal of Educational Research and Extension, 2(3).

8. Gupta, S.M. (1979). Standardization of a test of creativity in physical sciences. Unpublished doctoral dissertation, Kurukshetra University, Kurukshetra.

9. Haylock, D. W. (1987b). Mathematical creativity in school children. The Journal of Creative Behavior, 21(1), 49-59.

10. Kim, B. Y., Lee, J. S., \& Cho, J. H. (1999). On the Practice of Creativity Development in Middle High School Mathematics. In: Proceedings of 1999 Spring Meeting of Mathematics Education held at Ewha Womans Univ., June 26, 1999 (pp. 523-542). Seoul: Korea Society of Educational Studies in Mathematics.

11. Lee, K.S., Hwang, D.J., Seo, J.J. (2003). A development of the test for mathematical creative problem solving ability. Journal of the Korea Society of Mathematical Education Series D, 7(3), 163-189.

12. Manchanda, R. (2013). Effect of abacus arithmetic programme on creativity, achievement \&self confidence of students in mathematics. Unpublished doctoral dissertation, Kurukshetra University, Kurukshetra.

13. Mann, E. L. (2006). Creativity: The essence of mathematics. Journal for the Education of the Gifted, 30(2), 236-260.

14. Mehndi, B. (1973). Manual: Verbal and non verbal tests of creative thinking. Alligarh : Alligarh Publishers.

15. Miyan, M. (1982). A study to examine the effectiveness of methods of teaching mathematics in developing mathematical creativity. Unpublished doctoral dissertation, Jamia Millia Islamia University, New Delhi.

16. Passi, B. K. (1971). An exploratory study of creativity and its relationship with intelligence and achievement in school subjects at higher secondary stage. Unpublished doctoral dissertation, Panjab University, Chandigarh.

17. Prouse, H.L. (1964). The construction and use of a test for the measure of certain aspects of creativity in seventh-grade mathematics. Dissertation Abstracts, 26 (1), 394.

18. Sayed. \&Demerdash. (2008).Geometric creativity test. Published doctoral dissertation, The University of Education Schwabisch Gmund.

19. Sharma, Y., \& Sansanwal, D.N. (2012). Development and standardization of mathematical creativity test. The Mathematics Education, 36(4).

20. Sharma, Y., \& Sansanwal, D.N.: S2. (2011). Mathematical creativity test. Amritsar: Axiomatic Educational Services.

21. Singh, B. (1987). The development of tests to measure mathematical creativity. International Journal of Mathematics in Science and Technology, 18(2), 181-186.

22. Singh, B. (2003).Mathematical creativity research in India: A review. Indian Educational Review, 39(2), 3-21.

23. Tammagade. (1979). A. Creativity: Presidential address to the mathematical association. The Mathematical Gazzette, 63(425). 145.163. In Haylock, D. W. (1987b). Mathematical creativity in school children. The Journal of Creative Behavior, 21(1), 49-59. 


\section{Appendix A \\ MATHEMATICAL CREATIVITY TEST : FINAL DRAFT}

ITEM I: Write $1000 a^{5} b^{3}$ in different ways without changing the value.

ITEM II: Suppose you and your friend are playing a guessing game to determine the name of a geometric figure. In this game, your friend will think of figure and you will ask him questions about the figure. Your friend will respond. Your task is to put as many questions as you can which should be answered in order to determine the name of the figure.

ITEM III: Write as many relationships as you can between 64 and 144.

ITEM IV: Write similarities and dissimilarities between Rectangle and Rhombus the following figures. They are similar in certain aspects and different in another.

ITEM V: Write as many geometrical shapes, figures and concepts in relation to different objects which you observe in day to day life.

ITEM VI: Select few numbers from the given numbers $(1,2,3,4,8,9,16,24,27,28,32,36,40,43,44,48,49)$, showing some pattern or having relation with each other.

ITEM VII: Read the following mathematical situation carefully. Suppose you and your friend are playing in the rectangular park having a length $160 \mathrm{~m}$ and breadth $120 \mathrm{~m}$ is surrounded by a footpath having a width of $3 \mathrm{~m}$. The cost of fencing is Rs. 35 per meter. It needs to be cemented at the rate of Rs 120 per square meter. The cost of one bag of cement is Rs. 350. The grass lawn is divided into four sections by two intersecting paths having width of $2 \mathrm{~m}$. The path is also required to be tiled. 9 tiles of $15 \times 12 \mathrm{~cm}$ are required to cover $1 \mathrm{~m}^{2}$ area of footpath. There is one flowering bed of $8 \mathrm{~m} \times 8 \mathrm{~m}$ in one corner of each section of the grass lawn. Cost of planting flower in $4 \mathrm{~m}^{2}$ areas is Rs. 100. Now, your task is to frame as many problems as you can from the data given in problem as well as in diagram.

ITEM VIII: Suppose you have 12 pieces of wire of equal length. Name various geometrical shapes/figures which can be made by using these 12 pieces of wires. Write also the name of figure. 